\title{
Ternary coordination compounds of copper with amino acids and 1,10-phenanthroline - structural insight and biological activity
}

\author{
B. Prugovečki, D. Vušak, K. Ležaić and M. Jurković \\ University of Zagreb, Faculty of Science, Department of Chemistry, Horvatovac 102a, 10000 Zagreb, Croatia \\ biserka@chem.pmf.hr
}

Ternary coordination compounds of copper with amino acids / amino acid derivatives and heterocyclic bases are important in studies related to the biological activity and structural properties. They have potential application in biomedicine and crystal engineering[1,2]. Ternary coordination compounds with amino acids and heterocyclic bases as ligands possess many hydrogen bond acceptors and donors and form diverse but somehow predictable supramolecular motifs based on covalent bonds or noncovalent interactions (porous structures, coordination polymers or other arhitectures) [3-6].

As a part of our ongoing investigation of copper-amino acidato systems, we report 5 new crystal structures of ternary coordination compounds of copper(II) with 1,10-phenanthroline (Phen) and L-threonine (Thr) and sarcosine (Sar): $\left[\mathrm{Cu}(\mathrm{Sar})\left(\mathrm{H}_{2} \mathrm{O}\right)(\mathrm{Phen})\right]\left[\mathrm{Cu}\left(\mathrm{SO}_{4}\right)(\mathrm{Sar})(\mathrm{Phen})\right] \cdot \mathrm{Py} \cdot 2 \mathrm{H}_{2} \mathrm{O}$ $\left[\mathrm{Cu}(\mathrm{Sar})\left(\mathrm{H}_{2} \mathrm{O}\right)(\mathrm{Phen})\right]\left[\mathrm{Cu}\left(\mathrm{SO}_{4}\right)(\mathrm{Sar})(\mathrm{Phen})\right] \cdot 7 \mathrm{H}_{2} \mathrm{O}$

$\left[\mathrm{Cu}(\mathrm{Sar})\left(\mathrm{H}_{2} \mathrm{O}\right)_{2}(\mathrm{Phen})\right]\left[\mathrm{Cu}(\mathrm{Sar})\left(\mathrm{H}_{2} \mathrm{O}\right)(\mathrm{Phen})\right] \mathrm{SO}_{4} \cdot 8 \mathrm{H}_{2} \mathrm{O} \quad(\mathbf{3}), \quad\left\{[\mathrm{Cu}(\mu \text {-Thr })(\mathrm{Phen})]_{2} \mathrm{SO}_{4} \cdot 3.5 \mathrm{H}_{2} \mathrm{O}\right\}_{n} \quad(\mathbf{4}), \quad\left[\mathrm{Cu}(\mathrm{Thr})\left(\mathrm{H}_{2} \mathrm{O}\right)(\mathrm{Phen})\right]$ $[\mathrm{Cu}(\mathrm{Thr})(\mathrm{Py})(\mathrm{Phen})] \mathrm{SO}_{4} \cdot 2 \mathrm{H}_{2} \mathrm{O}(\mathbf{5})(\mathrm{Py}=$ pyridine). Except for one complex cation in compound $\mathbf{3}$ as well as in coordination polymer 4, the copper(II) ion is pentacoordinated by $N, O$-donating Thr or Sar ligand and $N, N$ '-donating Phen ligand in the basal plane and apically coordinated solvent molecule (water or pyridine) or sulphate anion. In one of complex cation in 3 the copper(II) ion is octahedrally coordinated with Sar and Phen ligands in equatorial positions and two water molecules in the axial positions. Compound 4 is a coordination polymer with the copper(II) ion pentacoordinated by didentate Thr and Phen ligands while the axial position is occupied by carboxylate oxygen atom from the neighbouring complex unit. In all crystal structures infinite double chains are formed through $\pi$ interactions of the neighbouring Phen rings, which are interconnected by extensive network of $\mathrm{O}-\mathrm{H} \cdots \mathrm{O}, \mathrm{N}-\mathrm{H} \cdots \mathrm{O}$ and/or $\mathrm{O}-\mathrm{H} \cdots \mathrm{N}$ hydrogen bonds. Except for compound 5, solvents molecules of crystallization are located in 1D channels (Figure 1.a). In $\mathbf{5}$ the water molecules of crystallization are located in pockets between double chains, and with sulpfate ions serve as hydrogen bond bridges between adjacent chains through $\mathrm{O}-\mathrm{H} \cdots \mathrm{O}$ and $\mathrm{N}-\mathrm{H} \cdots \mathrm{O}$ hydrogen bonds (Figure 1.b).

The cytotoxicity of copper coordination compounds was investigated on cultured HepG2 (human liver cancer) and THP-1 (human leukemia monocytic) cell lines. The compounds showed prominent cytotoxicity towards both cell lines.
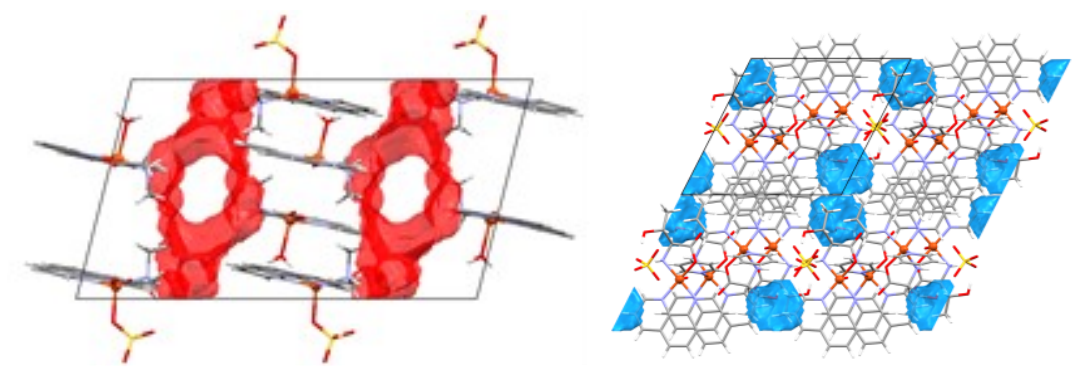

Figure 1. a) 1D channels of solvent molecules in 1, b) pockets of water molecules in 5.

[1] Lakshmipraba, J. et al. (2011) European Journal of Medicinal Chemistry, 46, 3013-3021.

[2] Zhang, S. \&. Zhou J. (2008) Journal of Coordination Chemistry 61(15), 2488-2498.

[3] Vušak, D. et al. (2017) Cryst. Growth Des. 17, 6049-6061.

[4] Maji, T. K. (2007) Pure Appl. Chem. 79(12), 2155-2177.

[5] Vušak, D. et al. (2019) Acta Cryst. A75, E530-E530.

[6] Vušak, D. et al. (2018) Acta Cryst. A74, E337-E337.

Keywords: coordination compounds, copper, L-threonine, phenanthroline, sarcosine 